\title{
Assessing Cancer Risk Associated with Aquatic Polycyclic Aromatic Hydrocarbon Pollution Reveals Dietary Routes of Exposure and Vulnerable Populations
}

\author{
Larisa M. Gearhart-Serna, ${ }^{1,2,3}$ Nishad Jayasundara, ${ }^{3,4}$ Moises Tacam Jr., ${ }^{5}$ \\ Richard Di Giulio, ${ }^{3}$ and Gayathri R. Devi $\mathbb{C}^{1,2,6}$ \\ ${ }^{1}$ Department of Surgery, Division of Surgical Sciences, Duke Cancer Institute, Duke University, Durham, NC, USA \\ ${ }^{2}$ Department of Pathology, Duke Cancer Institute, Duke University, Durham, NC, USA \\ ${ }^{3}$ Nicholas School of the Environment, Duke Cancer Institute, Duke University, Durham, NC, USA \\ ${ }^{4}$ School of Marine Sciences, University of Maine, ME, USA \\ ${ }^{5}$ Trinity School of Arts and Sciences, Duke Cancer Institute, Duke University, Durham, NC, USA \\ ${ }^{6}$ Women's Cancer Program, Duke Cancer Institute, Duke University, Durham, NC, USA \\ Correspondence should be addressed to Gayathri R. Devi; gayathri.devi@duke.edu
}

Received 23 January 2018; Revised 27 July 2018; Accepted 19 August 2018; Published 19 September 2018

Academic Editor: Riccardo Buccolieri

Copyright (c) 2018 Larisa M. Gearhart-Serna et al. This is an open access article distributed under the Creative Commons Attribution License, which permits unrestricted use, distribution, and reproduction in any medium, provided the original work is properly cited.

\begin{abstract}
Polycyclic aromatic hydrocarbon (PAH) exposure is widespread, and many PAHs are considered carcinogenic. The PAHcontaminated AWI Superfund site in Virginia provides a model for studying a complex PAH mixture and its extrapolation to cancer risk and PAH exposure in the general population. We examined cancer risk at the Superfund site due to sediment-derived PAHs and then evaluated PAH sources in the general population and potentially vulnerable subpopulations upon PAH mixture exposure. The PAH mixture was assessed for potential carcinogenicity using the US EPA's OncoLogic ${ }^{\mathrm{TM}}$ ranking tool and the US EPA list of priority PAHs. Cancer risk due to PAH exposure was calculated for Superfund site users and compared to the US EPA assessment. Human intake and health endpoints of PAHs within the mixture were extracted from USEtox ${ }^{\circledR}$ chemical fate database, while mean intake exposure was calculated for U.S. adults for select PAHs using NHANES database urinary biomarkers. Eleven PAH compounds within the mixture were of carcinogenic concern, and seven PAHs conveyed significant excess cancer risk at the Superfund site and in the general population, wherein PAH-contaminated seafood ingestion was a main contributor. Other dietary sources of PAHs derived from PAH-contaminated soil or water could also play a role in total exposure. Vulnerable populations to $\mathrm{PAH}$ exposure and coinciding increased cancer risk may include, in addition to smokers, children and nonHispanic blacks, which is a public health concern.
\end{abstract}

\section{Introduction}

From prenatal days until death, humans are each subjected to their own variable exposome [1], a sum of individual environmental exposures from their source to their biological and health effects [2-4]. Polycyclic aromatic hydrocarbons (PAHs) are highly carcinogenic, are also considered teratogenic and mutagenic, and may act as endocrine disrupting chemicals (EDCs). PAHs are released from anthropogenic and natural activities. $\mathrm{PAH}$ emissions and human exposure originate from sources of incomplete organic fuel combustion, including tobacco smoke, charred or smoked meat, industrial byproduct emissions, forest fires, volcanic eruptions, and even contaminated food [5]. While air emission sources such as tobacco smoke, and subsequent inhalation of volatile PAHs, has dominated analyses of exposure, dietary sources have been suggested as significant contributors to $\mathrm{PAH}$ exposure and potential health risks [6-9].

Single PAH chemical studies have been helpful in the research realm for studying toxicity, but realistic exposure to chemicals occurs in mixtures rather than by single 
chemicals. Therefore, mixture studies are necessary for relevance to actual human exposure. In this study, we model our investigations after previously obtained PAH-contaminated sediment samples derived from a Superfund site Atlantic Wood Industries (AWI) located in Portsmouth, Virginia, along the Southern Branch of the Elizabeth River. Superfund sites are commonly former industrial sites determined by the U.S. Environmental Protection Agency (US EPA) to be candidates for remediation due to contamination by hazardous wastes that pose a significant risk to human and environmental health. The AWI Superfund site was designated in 1990, following several decades of operations as a wood-treating facility. Subsurface soil, groundwater, and sediment contamination with PAHs has been recorded from AWI activities, including wood treatment, storage, and byproduct disposal. The original AWI Superfund site human health and ecological risk assessment identified a variety of chemicals contaminating the land and regions of the Elizabeth River which make up the site, including dioxins, PAHs, and several heavy metals [10]. Of note, extremely high levels of PAHs were measured in Elizabeth River sediments at the site relative to other Chesapeake Bay and worldwide estuarine areas of concern, suggesting that this site represents one of the most highly PAH-contaminated sites in the world [11]. This site provides an opportunity to study a complex PAH mixture that may represent a real-world exposure scenario.

There is a great need to analyze and mitigate risks due to $\mathrm{PAH}$ exposure, which has numerous human health consequences. In addition, matrices other than air must be analyzed for their contribution to PAH exposure, for example, soil and water matrices which may have a large impact on dietary $\mathrm{PAH}$ exposure. Based on the high level of PAHs and the complexity of the AWI Superfund site mixture, as well as the knowledge that many PAHs are carcinogenic, we postulated that the sediment-derived PAH mixture components would prove to be cancer relevant and confer cancer risk on the users of the Superfund site through various activities (e.g., fishing) relevant to sediment exposure. As this Superfund site mixture is a model complex PAH mixture that may occur in other regions, we further proposed that increased cancer risk and health effects would also be applicable for the wider U.S. population. Utilizing PAH urinary biomarkers from the U.S. CDC National Health and Nutrition Examination Survey (NHANES), a common method utilized successfully to estimate PAH exposure [12-14] and other biomarkers across the country with a statistical weighted approach [15], we have the capabilities to estimate and rank U.S. demographic subpopulations by PAH exposure, targeting those with high exposure for intervention efforts. This concept circles back to our broader hypothesis that PAH mixtures have the potential to increase cancer risk in the general population, especially for vulnerable and highly exposed populations, thus posing significant public health risks.

\section{Materials and Methods}

2.1. US EPA OncoLogic ${ }^{\mathrm{TM}}$ Carcinogenic Concern Analysis. $\mathrm{PAH}$ chemical components of the PAH Superfund mixture were individually run through the OncoLogic ${ }^{\mathrm{TM}}$ carcinogenic concern ranking tool [16], which is structure-based. $\mathrm{PAH}$ components that were present in the database and contained only a marginal or negligible carcinogenic concern ranking were not included in the results. OncoLogic ${ }^{\mathrm{TM}}$ uses structure-activity relationship (SAR) analysis to predict potential carcinogenicity, based upon structural- and biological-based carcinogenicity of various chemical classes. It incorporates both chemicalspecific input as well as knowledge-based rules developed by cancer and system development experts based on scientific publications and cancer studies. Carcinogenicity of mixture components were also assessed using the US EPA list of sixteen priority PAHs [17].

2.2. Superfund Site Cancer Risk Assessment Analysis. Risk is characterized by both exposure to and the potential human health hazard of a compound. In the original AWI Superfund site Record of Decision (ROD), operable unit 3 (OU3) was designed to account for human health risk due specifically to exposure to sediments on the site [18]. Five target groups of concern were trespassers (adult and child), recreational persons (swimmer/boater/crabber, adult, and child), and workers (i.e., dredge or other heavy equipment operators, spotter, barge worker, and adult). OU3 groups and assumptions are used for this assessment, but only trespassers and recreational adults and children are included in the final cancer risk assessment due to negligible risk calculated for workers wearing personal protective equipment. Seven major PAH contaminants of concern (COCs) in sediment were identified in the original site risk assessment based on calculated cancer risk and hazard indexes, which were benz[a]anthracene, benzo[a]pyrene $(\mathrm{BaP})$, benzo[b] fluoranthene, benzo[k]fluoranthene, chrysene, dibenz[a,h] anthracene, and indeno[1,2,3-c,d]pyrene. These seven COCs were used for our own subsequent cancer risk assessment based on AWI Superfund site sediment oral and dermal exposure. Equations used to calculate cancer risk are as follows:

$$
\begin{aligned}
& \text { Hazard }=\mathrm{CSF} * \mathrm{ADAF} \\
& \text { Exposure }_{\mathrm{oral}}=\mathrm{CDI}=\mathrm{CS} * \mathrm{IR}-\mathrm{S} * \mathrm{FI} * \mathrm{EF} * \mathrm{ED} * \mathrm{CF} * \\
& 1 / \mathrm{BW} * 1 / \mathrm{AT} \\
& \text { Exposure }_{\text {dermal }}=\mathrm{DAD}=\mathrm{DA}_{\text {event }} * \mathrm{EF} * \mathrm{ED} * \mathrm{EV} * \mathrm{SA} * \\
& 1 / \mathrm{BW} * 1 / \mathrm{AT} \\
& \mathrm{DA}_{\text {event }}=\mathrm{CS} * \mathrm{CF} * \mathrm{AF} * \mathrm{ABSd}
\end{aligned}
$$

Risk is a function of hazard multiplied by exposure. For acronyms relating to hazard and exposure calculations, please refer to Supplementary Table 1. Cancer risk calculations for the five groups of concern were completed using Monte Carlo analysis described below with the hazard and exposure factors described above and can be found in Supplementary Table 2 [19-24]. This cancer risk only accounts for direct oral or dermal sediment exposure. These cancer risk values were then compared to cancer risk values calculated for exposure to sediment in the original AWI Superfund site risk assessment performed by the US EPA, for the same seven PAH COCs. 
2.3. Monte Carlo Simulation Analysis. With risk assessment, there is always some degree of uncertainty. To account for this in our cancer risk calculations, we utilized a Monte Carlo simulation method. While the concentration of each PAH COC in sediment as well as their cancer slope factor was held constant, several parameters of exposure were considered a variable. Body weight was considered a variable. For oral exposure, the ingestion rate, exposure frequency, and exposure duration were randomized for simulation using minimum and maximum quantitations in Table 1. For dermal exposure, the exposure frequency, exposure duration, soil to skin adherence factor, and surface area available for contact were randomized for simulation using minimum and maximum quantitations in Table 1. While standardized values for these variables are set based on US EPA exposure factors guidelines and professional judgement, $25 \%$ of error rates were factored into each variable to provide minimum and maximum distributions. 10,000 iterations were calculated for each group: trespasser adults, trespasser children, recreational adults, and recreational children. Results are shown as histograms of distribution and descriptive statistics for each group and exposure route.

\subsection{USEtox ${ }^{\circledR}$ Chemical Fate and Human Health Analysis.} Environmental fate and human intake data were pulled for 7 of the 36 PAHs present in the Superfund site PAH mixture from the USEtox ${ }^{\circledR}$ chemical fate modeling results database. These 7 PAHs are the same as the COCs identified in the Superfund site risk assessment. Intake from fresh water, sea water, natural soil, and agricultural soil was summed to reflect a mixture of all 7 PAHs and can be found in Supplementary Table 3. This intake was distributed by exposure route: inhalation, drinking water, produce, meat and dairy, and fish. Human health characterization data were also pulled in the form of excess cancer cases per kg emitted and daily adjusted life years for each of the seven Superfund site sediment PAH COCs and pooled to reflect excess cancer cases due to $\mathrm{PAH}$ mixture exposure, dependent on the environmental compartment into which the mixture is emitted.

2.5. Human Intake Exposure Analysis. Metabolite concentrations for four select PAHs were obtained from a National Health and Nutrition Examination Survey (NHANES) database report [25]. Concentrations were stratified into groups by gender (male/female), race (non-Hispanic white, non-Hispanic black, and Mexican American), and smoking status (smoker, nonsmoker, and exposed to secondhand smoke in the home). These concentrations were reported as the unadjusted geometric means of the entire population measured from 2003 to 2008. These PAHs are naphthalene, fluorene, phenanthrene, and pyrene, all present in high concentrations in the complex Superfund-derived PAH mixture. Excretion fractions of these PAHs in urine were obtained from the literature $[26,27]$, as well as standardized daily adult urine output [28] and adult body weight [21]. Using a back-of-the-envelope reverse dosimetry pharmacokinetic equation model described previously [29], we constructed estimated daily intake exposure for these four PAHs: exposure intake rate $(\mu \mathrm{g} / \mathrm{kg}$-day $)=\left(\right.$ concentration $_{\text {urine metabolite }} \times$ daily adult urine output $\left.\times \mathrm{MW}_{\text {parent }}\right) /($ urinary excretion fraction $\times$ adult body weight $\left.\times \mathrm{MW}_{\text {metabolite }}\right)$.

\section{Results and Discussion}

3.1. Polycyclic Aromatic Hydrocarbons Are Present in Superfund Sediment and Are Cancer Relevant. In order to assess the cancer relevance of our Superfund site PAH mixture, the 36 known PAH chemical components in the mixture [30] were assessed for potential carcinogenicity. Most importantly, we report the cancer relevance of many of the PAH chemicals in the AWI Superfund site sediment mixture based on rankings by the US EPA and the OncoLogic ${ }^{\mathrm{TM}}$ database tool. All 16 PAH chemicals on the US EPA list of priority PAHs [17] were present in the AWI sediment mixture. Furthermore, several PAHs within this PAH mixture also ranked at least low or low-moderate carcinogenic concern level by the US EPA OncoLogic ${ }^{\mathrm{TM}}$ ranking tool of carcinogenic concern (Table 2). Additionally, there may be potential synergy between PAH compounds with different biological targets. For example, high-affinity PAH cytochrome $\mathrm{p} 450$ inhibitors and aryl hydrocarbon receptor (AhR) agonists have previously been found to work together to increase toxicity through the AhR pathway in developmental toxicity models $[31,32]$. Thus, we could potentially be underestimating the carcinogenic concern of the mixture as a whole. Taken together, this information reveals the considerable carcinogenic concern of the AWI superfund-derived PAH mixture as a whole.

3.2. Seafood PAH Exposure Drives Cancer Risk at the Superfund Site. The original US EPA AWI Superfund site risk assessment was based on several exposure factors, which accounted for direct sediment ingestion and dermal contact exposure, as well as indirect exposure from eating meat of crab and oyster from the site. From the cancer risks calculated therein, the assessment identified seven PAH contaminants of concern (COCs) that accounted for a majority of the cancer risk (Figure 1(a)). Of the total cancer risk due to the AWI sediment exposure, for all sediment components, over $90 \%$ was attributable to the PAH composition of the contaminated sediment for each group of concern, trespasser and recreational user adults and children of the Superfund site (Figure 1(b)). In our study related to the AWI sediment exposure assessment, cancer risks were calculated for each group of concern due to sediment exposure to the seven COCs, utilizing Monte Carlo simulations to estimate cancer risks. We utilized a standard $25 \%$ variability on exposure factors such as visits per day to the site and ingestion rates, due to known fluctuation but uncertain range distributions (Table 1). For these simulations, we only calculated risks due to direct oral ingestion or dermal exposure to PAH-contaminated sediments. We observed that our mean cancer risk calculations were orders of magnitude lower than the original US EPA cancer risk assessment to the 
TABLE 1: Monte Carlo simulation variables and distributions for cancer risk assessment due to oral and dermal sediment exposure at the AWI Superfund site.

\begin{tabular}{|c|c|c|c|c|c|c|}
\hline Parameter & Symbol & Units & Distribution-AT & Distribution-CT & Distribution-AR & Distribution-CR \\
\hline Concentration of 7 PAHs in sediment & CS & $\mathrm{mg} / \mathrm{kg}$ & 0.283 & 0.283 & 0.283 & 0.283 \\
\hline Average time-Cancer & AT & days & 25550 & 25550 & 25550 & 25550 \\
\hline Age-dependent adjustment factor & ADAF & Unitless & 1 & 10 & 1 & 10 \\
\hline Conversion factor & $\mathrm{CF}$ & Unitless & 0.000001 & 0.000001 & 0.000001 & 0.000001 \\
\hline Body weight & BW & $\mathrm{kg}$ & $80 \pm 20$ & $15 \pm 3.75$ & $80 \pm 20$ & $15 \pm 3.75$ \\
\hline \multicolumn{7}{|l|}{ Oral exposure } \\
\hline Benzo(a)anthracene cancer slope factor & $\mathrm{BaA}$ & $\mathrm{mg} / \mathrm{kg}$-day & $7.30 E-01$ & $7.30 E-01$ & $7.30 E-01$ & $7.30 E-01$ \\
\hline Benzo(a)pyrene cancer slope factor & $\mathrm{BaP}$ & $\mathrm{mg} / \mathrm{kg}$-day & $7.30 E+00$ & $7.30 E+00$ & $7.30 E+00$ & $7.30 E+00$ \\
\hline Benzo(b)fluoranthene cancer slope factor & $\mathrm{BbF}$ & $\mathrm{mg} / \mathrm{kg}$-day & $7.30 E-01$ & $7.30 E-01$ & $7.30 E-01$ & $7.30 E-01$ \\
\hline Benzo(k)fluoranthene cancer slope factor & $\mathrm{BkF}$ & $\mathrm{mg} / \mathrm{kg}$-day & $7.30 E-02$ & $7.30 E-02$ & $7.30 E-02$ & $7.30 E-02$ \\
\hline Chrysene cancer slope factor & Chr & $\mathrm{mg} / \mathrm{kg}$-day & $7.30 E-03$ & $7.30 E-03$ & $7.30 E-03$ & $7.30 E-03$ \\
\hline Dibenz(a,h)anthracene cancer slope factor & Dib & $\mathrm{mg} / \mathrm{kg}$-day & $7.30 E+00$ & $7.30 E+00$ & $7.30 E+00$ & $7.30 E+00$ \\
\hline Indeno(1,2,3-c,d)pyrene cancer slope factor & Ind & $\mathrm{mg} / \mathrm{kg}$-day & $7.30 E-01$ & $7.30 E-01$ & $7.30 E-01$ & $7.30 E-01$ \\
\hline Exposure frequency & $\mathrm{EF}$ & days/year & $40 \pm 10$ & $52 \pm 13$ & $32 \pm 8$ & $48 \pm 12$ \\
\hline Exposure duration & ED & years & $20 \pm 5$ & $6 \pm 1.5$ & $20 \pm 5$ & $6 \pm 1.5$ \\
\hline Ingestion rate-sediment & IR-S & $\mathrm{mg} / \mathrm{day}$ & $20 \pm 5$ & $50 \pm 12.5$ & $20 \pm 5$ & $50 \pm 12.5$ \\
\hline \multicolumn{7}{|l|}{ Dermal exposure } \\
\hline Benzo(a)anthracene & $\mathrm{BaA}$ & $\mathrm{mg} / \mathrm{kg}$-day & $2.50 E+00$ & $2.50 E+00$ & $2.50 E+00$ & $2.50 E+00$ \\
\hline Benzo(a)pyrene cancer slope factor & $\mathrm{BaP}$ & $\mathrm{mg} / \mathrm{kg}$-day & $2.50 E+01$ & $2.50 E+01$ & $2.50 E+01$ & $2.50 E+01$ \\
\hline Benzo(b)fluoranthene cancer slope factor & $\mathrm{BbF}$ & $\mathrm{mg} / \mathrm{kg}$-day & $2.50 E+00$ & $2.50 E+00$ & $2.50 E+00$ & $2.50 E+00$ \\
\hline Benzo(k)fluoranthene cancer slope factor & $\mathrm{BkF}$ & $\mathrm{mg} / \mathrm{kg}$-day & $2.50 E-01$ & $2.50 E-01$ & $2.50 E-01$ & $2.50 E-01$ \\
\hline Chrysene cancer slope factor & Chr & $\mathrm{mg} / \mathrm{kg}$-day & $2.50 E-02$ & $2.50 E-02$ & $2.50 E-02$ & $2.50 E-02$ \\
\hline Dibenz(a,h)anthracene cancer slope factor & Dib & $\mathrm{mg} / \mathrm{kg}$-day & $2.50 E+01$ & $2.50 E+01$ & $2.50 E+01$ & $2.50 E+01$ \\
\hline Indeno(1,2,3-c,d)pyrene cancer slope factor & Ind & $\mathrm{mg} / \mathrm{kg}$-day & $2.50 E+00$ & $2.50 E+00$ & $2.50 E+00$ & $2.50 E+00$ \\
\hline Exposure frequency & $\mathrm{EF}$ & days/year & $40 \pm 10$ & $52 \pm 13$ & $32 \pm 8$ & $48 \pm 12$ \\
\hline Exposure duration & $\mathrm{ED}$ & years & $20 \pm 5$ & $6 \pm 1.5$ & $20 \pm 5$ & $6 \pm 1.5$ \\
\hline Soil to skin adherence & $\mathrm{AF}$ & $\mathrm{mg} / \mathrm{cm}^{2}$-day & $0.07 \pm 0.0175$ & $0.2 \pm 0.05$ & $0.2 \pm 0.05$ & $0.07 \pm 0.0175$ \\
\hline Dermal absorption fraction & ABSd & Unitless & 0.13 & 0.13 & 0.13 & 0.13 \\
\hline Skin surface area available for & SA & $\mathrm{cm}^{2}$ & $6032 \pm 1508$ & $2373 \pm 593.25$ & $6032 \pm 1508$ & $2373 \pm 593.25$ \\
\hline
\end{tabular}

$\mathrm{AT}=$ adult trespasser; $\mathrm{CT}=$ child trespasser; $\mathrm{AR}=$ adult recreational user; $\mathrm{CR}=$ child recreational user.

seven sediment PAH COCs (Figures 1(c) and 1(d)). In both the US EPA and our assessment, children had higher cancer risk than adults due to this AWI Superfund PAH mixture exposure for both trespassers and recreational users of the site. 95\% confidence intervals of associated cancer risk revealed reliable risk calculations, with less than $0.03 \mathrm{E}-07$ range between lower and upper bounds and steep bell curve models when shown by histogram. In addition, oral and dermal exposure simulation distributions for all groups of concern were left-skewed, with larger variability from dermal exposure routes (Figures 2(a)-2(c)). Variability was set at $25 \%$, so we were limited in that risk assessment variables with larger ranges (i.e., body weight, exposure frequency, and body surface area) having larger effects on cancer risk.

While we had complete information on ingestion and dermal risk assessment parameters, we had no data regarding current seafood intake or parameters for the Superfund site. However, the difference in cancer risk between assessments is likely due to our cancer risk assessment not accounting for the indirect exposure to crab and oyster meat from the original risk assessment, since this was the only large difference between the two assessments. When this seafood exposure was taken into account in the original assessment, total cancer risk due to sediment exposure exceeded $10^{-4}$ for both adult and child trespassers and recreational users of the site, which is the threshold safe cancer risk as defined by the US EPA. Taken together, the results suggest that the sediment-derived $\mathrm{PAH}$ mixture obtained for this experiment is of carcinogenic concern in a real-world setting, with contaminated seafood ingestion as the largest contributor to $\mathrm{PAH}$ exposure. In translating this knowledge to the broader public, contaminated seafood dietary ingestion could be a significant source of exposure to PAH mixtures.

3.3. PAH Intake Exposure Varies by Environmental Compartment Source. The AWI Superfund site is currently closed for remediation, although adjacent sites are under evaluation for similar PAH contamination levels. In addition, the mixture described previously from Superfund site sediment represents a complex PAH mixture which could be present anywhere in varying amounts, more broadly applicable to the wider human population. We next analyzed the PAH mixture for potential increase in cancer incidence in this larger human population. To do this, we utilized the USEtox $^{\circledR}$ PAH chemical fate database, and the fate schematic from emission to human intake used for the database calculations is shown in Figure 3(a). The PAH mixture 
TABLE 2: Cancer-relevant polycyclic aromatic hydrocarbons are present in Superfund sediment, as determined by US EPA priority PAHs list and OncoLogic ${ }^{\mathrm{TM}}$ carcinogenicity ranking tool.

\begin{tabular}{|c|c|c|c|c|}
\hline & $\begin{array}{l}\text { Concentration* } \\
(\mathrm{ng} / \mathrm{mL})\end{array}$ & $\begin{array}{l}\text { Standard deviation } \\
(\mathrm{ng} / \mathrm{mL})\end{array}$ & $\begin{array}{c}\text { US EPA } \\
\text { priority PAH }\end{array}$ & $\begin{array}{c}\text { OncoLogic }{ }^{\mathrm{TM}} \text { carcinogenic } \\
\text { concern level }\end{array}$ \\
\hline Naphthalene & 1617.2 & 341.2 & + & \\
\hline Phenanthrene & 597.1 & 171.7 & + & Low \\
\hline Fluoranthene & 422.6 & 35.7 & + & \\
\hline Acenaphthene & 404.7 & 96.4 & + & Low \\
\hline Fluorene & 321.2 & 188.5 & + & \\
\hline Pyrene & 288.0 & 21.4 & + & Low \\
\hline Carbazole & 246.0 & 60.1 & & \\
\hline Dibenzofuran & 207.7 & 82.9 & & \\
\hline 1-Methylnaphthalene & 161.5 & 31.7 & & \\
\hline Benz(a)anthracene & 77.6 & 7.8 & + & Low-moderate \\
\hline Anthracene & 73.1 & 12.1 & + & \\
\hline Benzo(b)fluoranthene & 66.1 & 4.8 & + & Moderate-high \\
\hline Dibenzothiophene & 63.4 & 49.8 & & \\
\hline Chrysene & 62.0 & 4.7 & + & \\
\hline 1,2-Benzofluorene & 46.5 & 4.1 & & \\
\hline 2,6-Dimethylnaphthalene & 44.7 & 39.4 & & \\
\hline Benzo(a)pyrene & 44.3 & 2.4 & + & High \\
\hline Retene & 43.8 & 3.6 & & \\
\hline 2-Methylphenanthrene & 39.8 & 10.7 & & \\
\hline Benzo(e)pyrene & 31.2 & 7.3 & & \\
\hline Benzo(k)fluoranthene & 26.6 & 1.7 & + & Low-moderate \\
\hline 1-Methylphenanthrene & 20.5 & 3.1 & & \\
\hline Acenaphthylene & 17.0 & 8.5 & + & \\
\hline Benzo(g,h,i)perylene & 14.7 & 1.3 & + & \\
\hline Picene & 14.2 & 1.2 & & Moderate \\
\hline 3,4-Benzofluorene & 9.0 & 3.0 & & \\
\hline Perylene & 8.8 & 0.8 & & Low \\
\hline Benzo(a)fluoranthene & 6.9 & 0.7 & & Low-moderate \\
\hline Dibenz(a,l)pyrene & 6.2 & 0.5 & & High \\
\hline Indeno $(1,2,3-c, d)$ pyrene & 3.6 & 0.5 & + & Moderate \\
\hline Benzo(b)chrysene & 3.5 & 0.4 & & \\
\hline $\operatorname{Dibenz}(\mathrm{a}, \mathrm{j})$ anthracene & 2.8 & 0.6 & & Moderate \\
\hline Dibenz(a,h)anthracene & 2.8 & 0.6 & + & High \\
\hline Benzo(c)phenanthrene & 2.4 & 0.3 & & Low-moderate \\
\hline 3-Methylcholanthrene & 0.0 & 0.0 & & \\
\hline
\end{tabular}

*Concentrations determined by mass spectrometry in previous study [22].

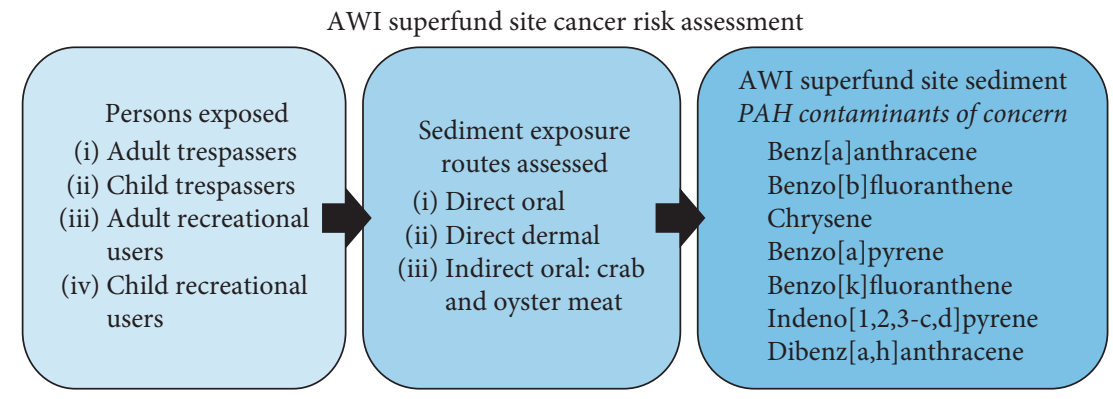

(a)

Figure 1: Continued. 


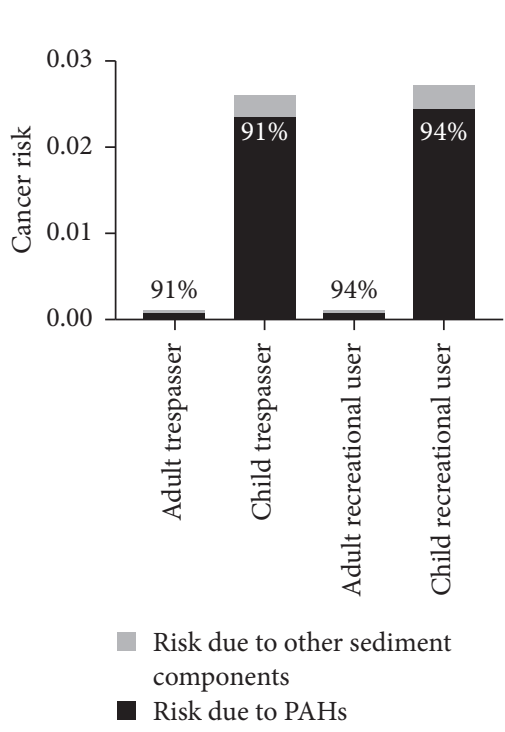

(b)

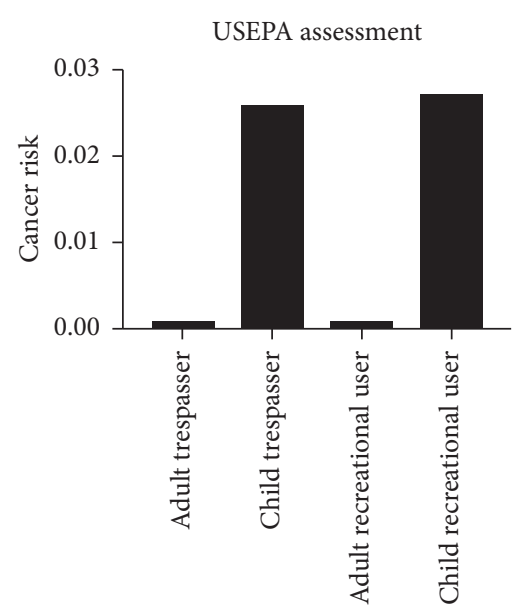

(c)

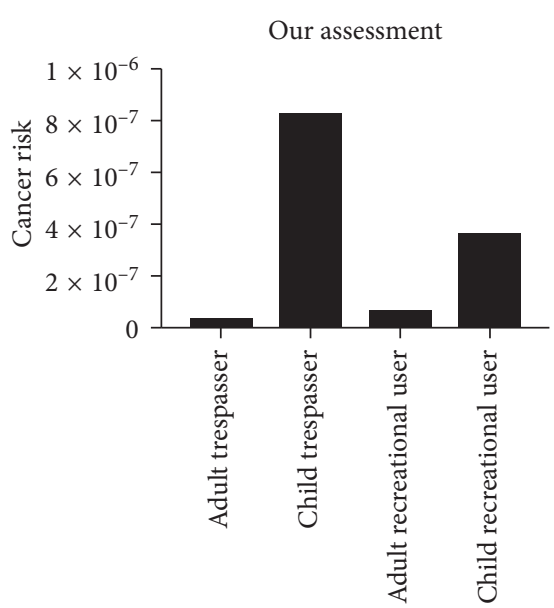

(d)

FIGURE 1: Indirect PAH exposure drives sediment-based cancer risk at the Superfund site. (a) Schematic calculation design of the original Superfund site cancer risk assessment due to sediment exposure, whereas our assessment does not take into account indirect oral exposure. Also includes the seven PAH contaminants of concern in sediment utilized for the cancer risk assessment, both AWI and our assessment. (b) Total cancer risk calculated in the original AWI risk assessment at the Superfund site due to sediment exposure, with the percentage of that cancer risk due to PAH or other contaminant exposure. Cancer risk due to Superfund site sediment exposure as calculated in the original AWI Superfund site risk assessment (c) and as calculated in our direct exposure assessment (d) in this experiment.
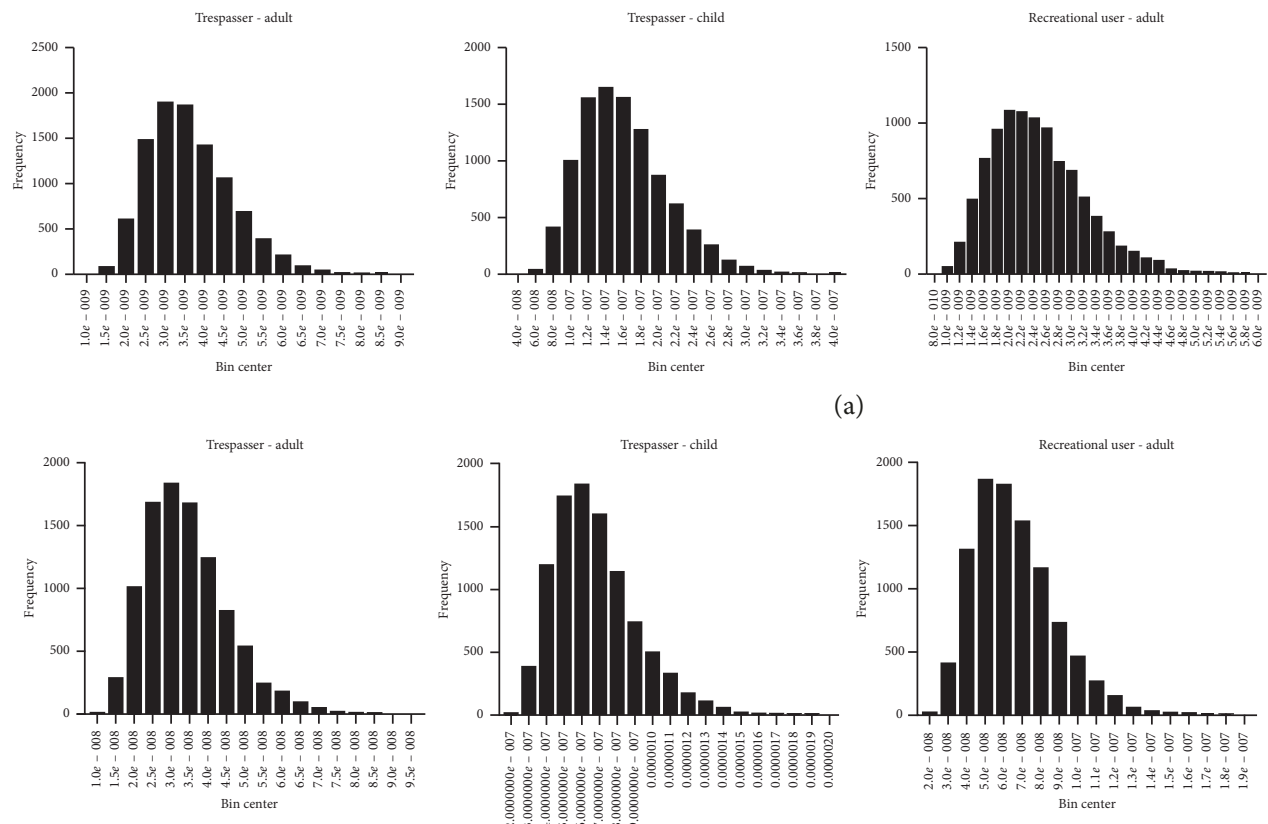

(a)
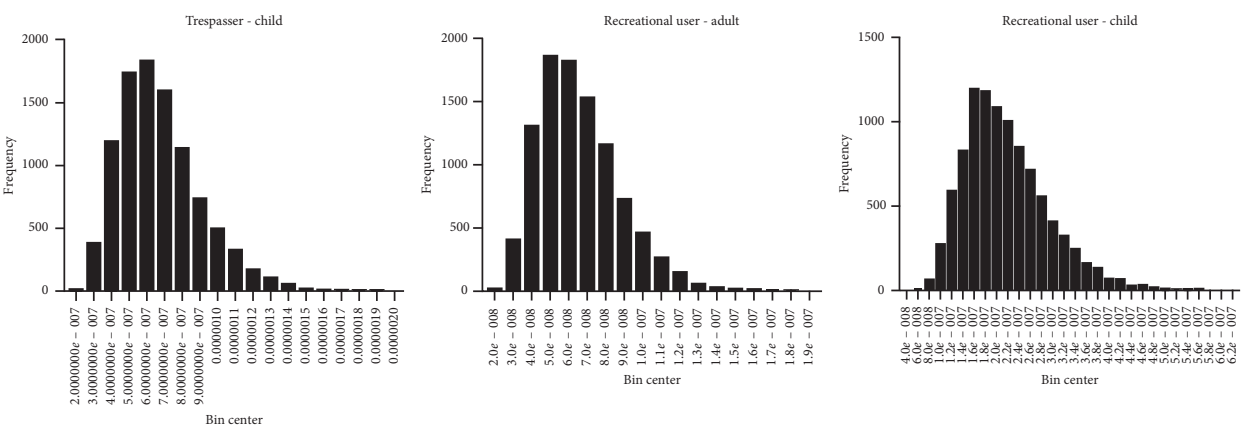

(b)

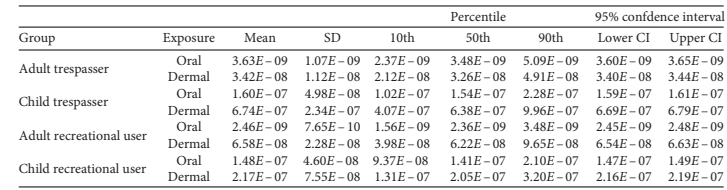

(c)

Figure 2: Monte Carlo simulation of cancer risk at the AWI Superfund site. Histograms of cancer risk distribution due to (a) oral exposure and (b) dermal exposure to seven PAH COCs in AWI Superfund site sediment by adult trespassers, child trespassers, adult recreational users, and child recreational users. (c) Descriptive statistics table of cancer risk distributions from Monte Carlo Simulation. COC $=$ contaminant of concern. 


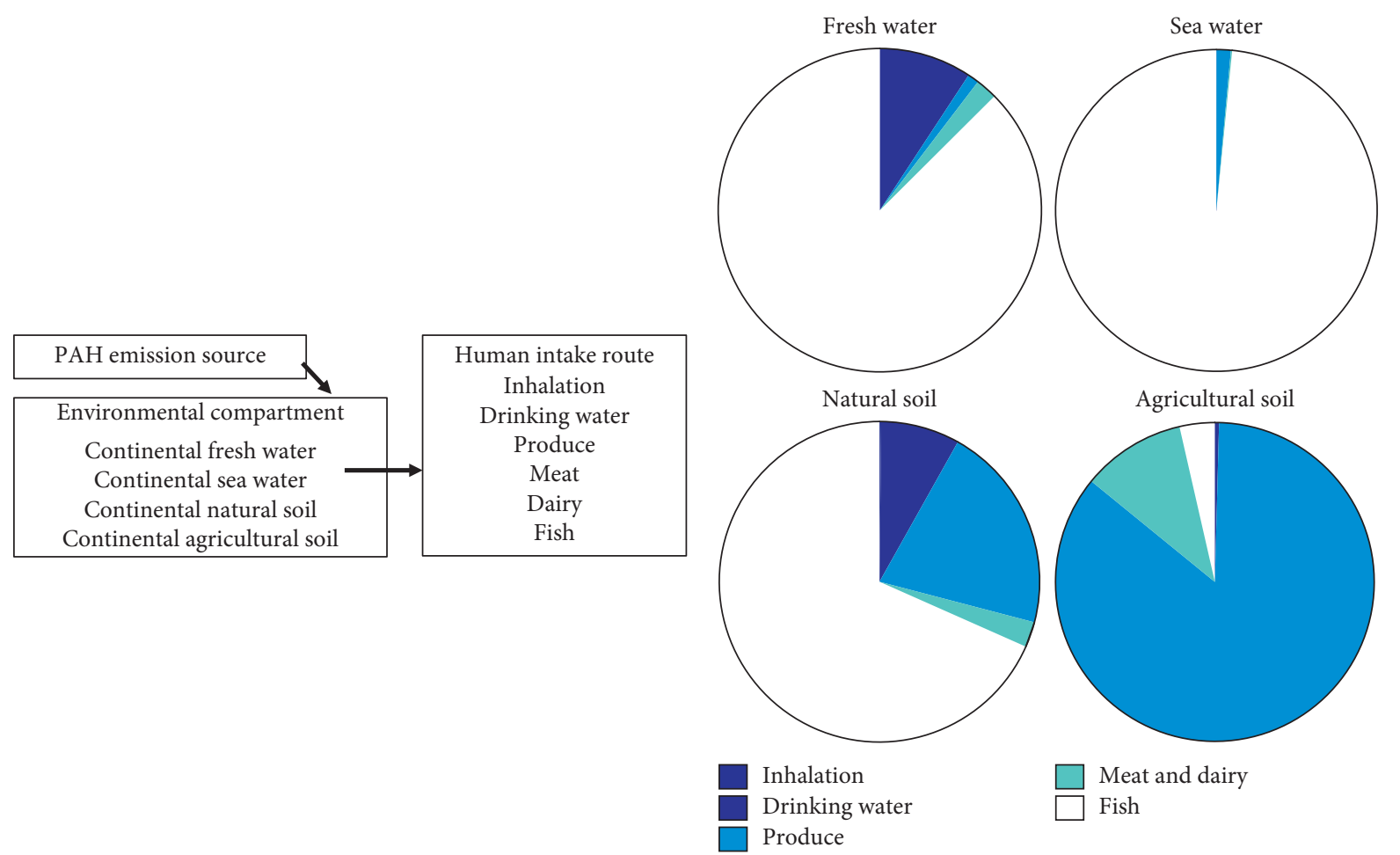

(a)

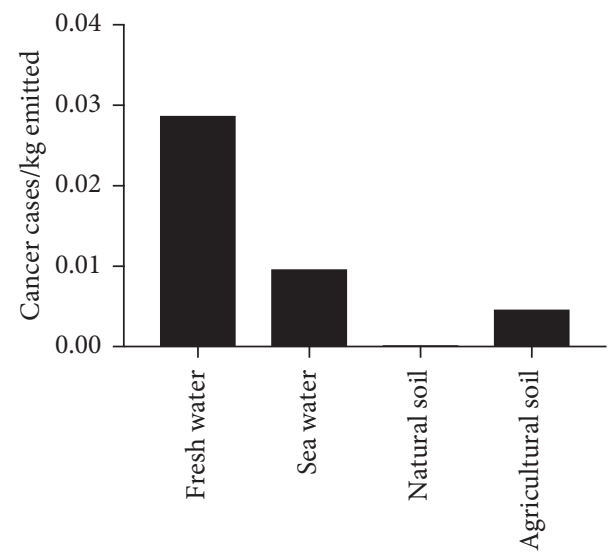

(c) (b)

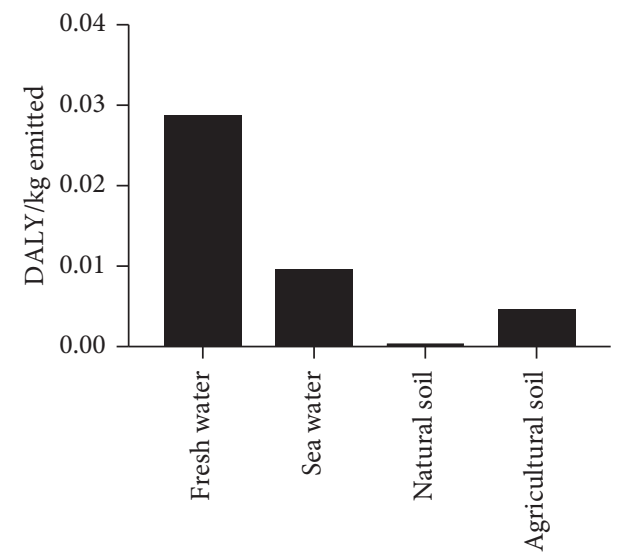

(d)

FIGURE 3: PAH mixture exposure varies in the human population depending on source: (a) chemical fate modeling of PAHs in the environment from emission source to environmental compartment to human intake route, as utilized in the USEtox model; (b) USEtox database distribution of human intake of a mixture of 7 PAH COCs. Human intake is measured by inhalation, drinking water, produce, meat and dairy, or fish, depending on the environmental compartment into which the PAH is emitted; (c) cancer cases and (d) daily adjusted life year (DALY) per kg emitted into different environmental compartments for a PAH mixture containing the seven Superfund site sediment contaminants of concern.

considered in these intake analyses included the $7 \mathrm{PAH}$ COCs found in the Superfund sediment PAH mixture.

USEtox ${ }^{\circledR}$ chemical fate database intake factors revealed that $\mathrm{PAH}$ exposure in the general human population can occur via multiple routes, and human exposure to PAHs varies depending on where the PAH is emitted. For this study, we focused on soil and water matrices, closely applicable to our Superfund sediment-derived PAH mixture. For example, if the PAH mixture is emitted into continental fresh water, continental sea water, or continental natural soil, the mixture is taken in by humans primarily through fish, which is consistent with the increased cancer risk seen at the Superfund site due to contaminated sediment exposure. PAH mixture intake can also occur through drinking water and produce (Figure 2(b)). Thus, lifestyle and diet factors can substantially impact an individual's exposure to these PAH chemicals.

USEtox ${ }^{\circledR}$ also allows analysis of midpoint and endpoint human health effects due to chemical emission and exposure. Cancer cases and daily adjusted life year (DALY, life lost due to disability or death) per kg emitted of a PAH 


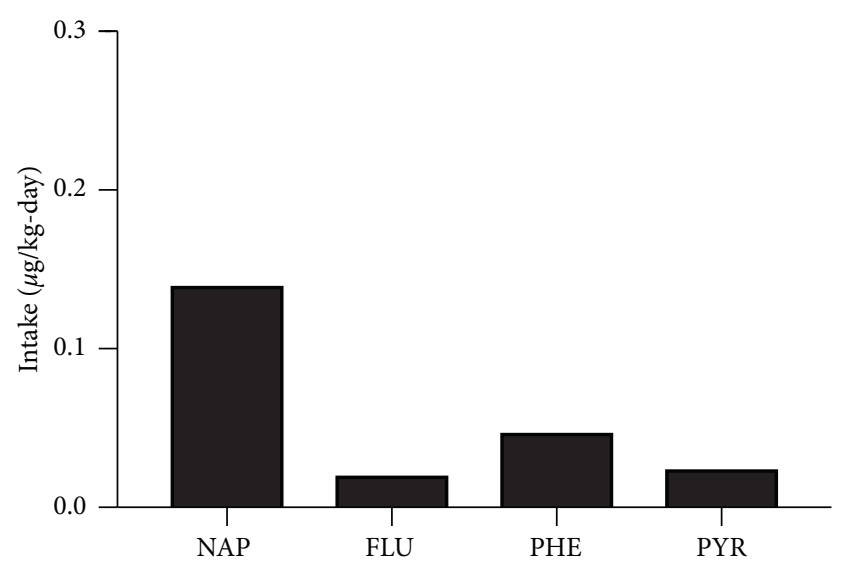

(a)

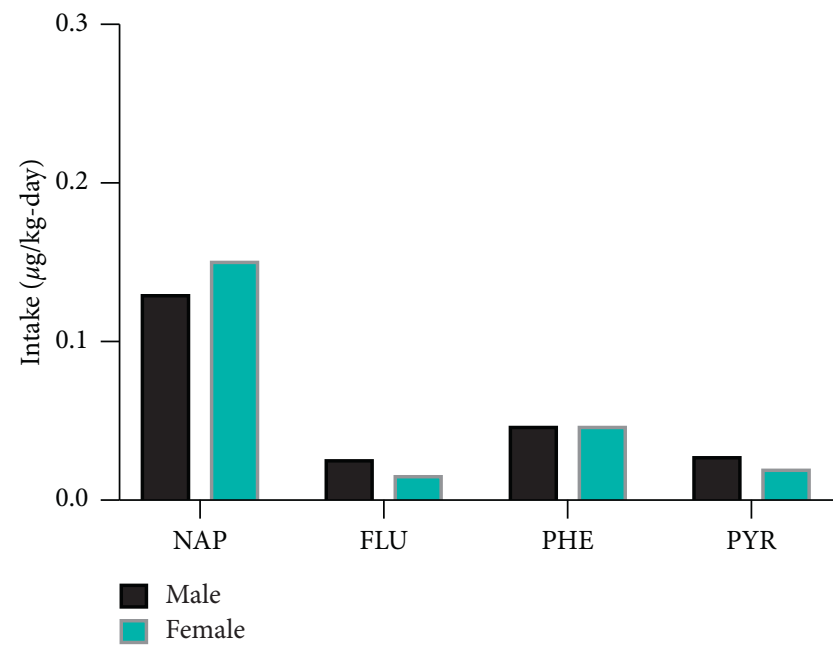

(c)

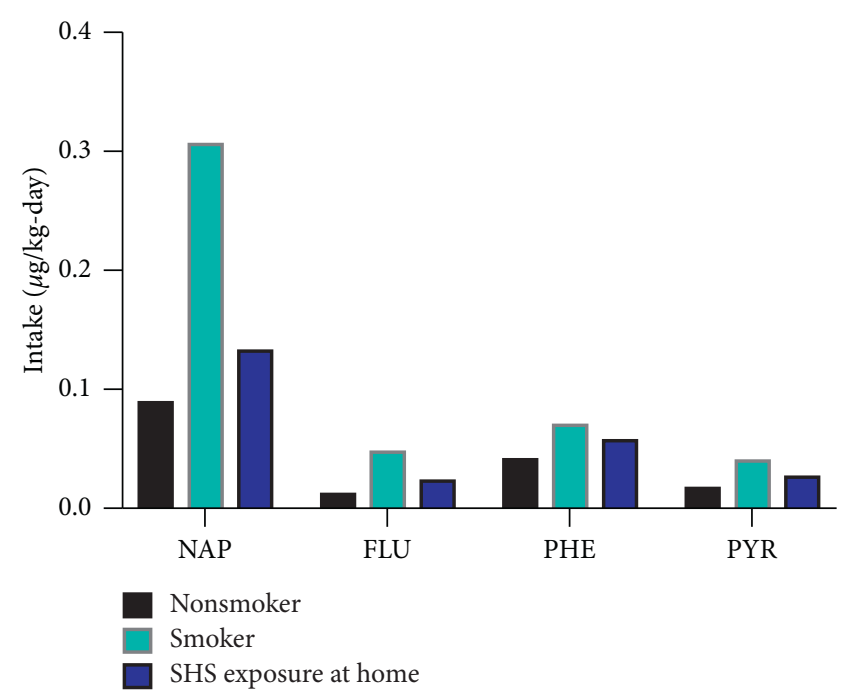

(b)

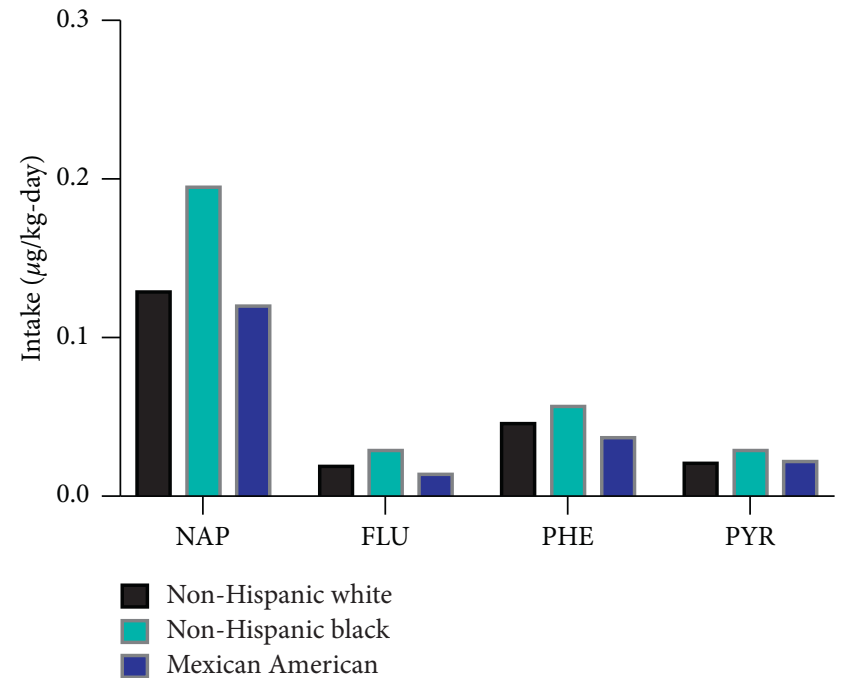

(d)

FIgURE 4: Intake exposure modeling of select PAHs for U.S. adults. Mean intake exposure ( $\mu \mathrm{g} / \mathrm{kg}$-day) calculated for (a) all 2003-2008 NHANES participants and stratified by (b) smoking status, (c) gender, or (d) race/ethnicity.

mixture comprised of the same seven COCs in the Superfund site sediment varied depending on where the PAHs are sourced. The largest cancer risk and DALY came from emission into household indoor air (data not shown), but fresh water also increased cancer cases and DALY based on PAH mixture emissions, followed in magnitude by sea water, agricultural soil, and natural soil (Figure 2(c)). Taken together, the data from this database reveal that a complex PAH mixture similar to our Superfund-derived example can affect human health by potentially increasing cancer cases and DALY, and that exposure to PAHs is widespread and highly variable in terms of source and intake.

3.4. Certain Demographic Subpopulations Have Higher PAH Exposure. Perhaps one of the most important considerations when analyzing $\mathrm{PAH}$ exposure is to analyze human subpopulations most at risk for exposure, for the greatest translation and impact on public health interventions. We conducted reverse dosimetry modeling to estimate $\mathrm{PAH}$ intake exposure based on urinary biomarkers of four PAHs (naphthalene, fluorene, phenanthrene, and pyrene) available in the U.S. CDC NHANES database. Urinary PAH biomarkers have previously been used to estimate exposure, and although PAHs vary seasonally and potentially by the time of urine collection, they provide us with a method to rank subpopulations in terms of exposure rather than just providing exposure quantitations. Additionally, NHANES provides the best available data on PAH biomarkers across a wide range of U.S. adult residents, thus providing a great value to the estimation of exposure across the human population.

Naphthalene, the simplest and most prolific PAH compound, constituted the largest portion of exposure to the four PAHs (Figure 4(a)). Not surprisingly, when separated by the 
smoking status, users of tobacco smoke had much higher exposure than nonsmokers, and those exposed to secondhand smoke were also exposed more than nonsmokers (Figure 4(b)). Once stratified by demographics factors gender and race/ ethnicity, neither males nor females had significantly higher exposure to any of the four PAHs (Figure 4(c)), but nonHispanic blacks had higher exposure for all four PAHs than other populations (Figure 4(d)). These analyses do not take into account subgroup interactions, for example, racial/ethnic groups that may be more highly exposed to PAHs when also smokers. However, our findings speak to the potential existence of vulnerable populations to PAH exposure, and the toxic effects included therein, including increased cancer risk. These subpopulations may be targeted in future studies and intervention efforts to reduce exposure.

\section{Conclusion}

In sum, we see increased cancer risk for children at the Superfund site, and in general, the majority of cancer risk comes from seven PAH COCs and contaminated seafood ingestion. We also see that this exposure can vary greatly in the general human population depending on where the PAHs are emitted and how they are taken in, and that nonHispanic black subpopulations in addition to smokers may be especially vulnerable to toxic effects and cancer risk due to $\mathrm{PAH}$ mixture exposure. This has major implications for public health and chemical exposure disparities.

\section{Data Availability}

Data collected for this study are freely available in US EPA reports on Atlantic Wood Industries, the USEtox database, and other public domains.

\section{Conflicts of Interest}

The authors declare that there are no conflicts of interest.

\section{Authors' Contributions}

GRD and RDG were responsible for design and oversight. LMGS and MT conducted experiments and database analyses. NJ provided assistance and consultation. LMGS and GRD provided oversight of the project and completion of this manuscript.

\section{Acknowledgments}

This research was supported in part by developmental funds from the Duke Cancer Institute (P3917733 and P30CA014236 to GRD) and Department of Surgery Bolognesi Award (to GRD). LMGS was supported by the training grant NIEHS T32-ES021432 and as part of the projects in NIH Award P20CA202924 (to GRD).

\section{Supplementary Materials}

Supplementary Table 1: AWI Superfund site cancer risk, hazard, and exposure acronym explanations, values, and data sources. Supplementary Table 2: raw exposure and cancer risk calculations for users of the AWI Superfund site by contaminant of concern. (Supplementary Materials)

\section{References}

[1] C. P. Wild, "Complementing the genome with an "exposome": the outstanding challenge of environmental exposure measurement in molecular epidemiology," Cancer Epidemiology Biomarkers \& Prevention, vol. 14, no. 8, pp. 1847-1850, 2005.

[2] P. J. Lioy and S. M. Rappaport, "Exposure science and the exposome: an opportunity for coherence in the environmental health sciences," Environmental Health Perspectives, vol. 119, no. 11, pp. a466-a467, 2011.

[3] G. W. Miller and D. P. Jones, "The nature of nurture: refining the definition of the exposome," Toxicological Sciences, vol. 137, no. 1, pp. 1-2, 2013.

[4] S. M. Rappaport, "What is the exposome," Cancer, vol. 22, no. 11, 2013.

[5] A. Ramesh, A. E. Archibong, D. B. Hood, Z. Guo, and B. G. Loganathan, "Global environmental distribution and human health effects of polycyclic aromatic hydrocarbons," in Global Contamination Trends of Persistent Organic Chemicals, pp. 97-126, CRC Press, Boca Raton, FL, USA, 2011.

[6] T. J. Buckley and P. J. Lioy, "An examination of the time course from human dietary exposure to polycyclic aromatic hydrocarbons to urinary elimination of 1-hydroxypyrene," Occupational and Environmental Medicine, vol. 49, no. 2, pp. 113-124, 1992.

[7] H. Alomirah, S. Al-Zenki, S. Al-Hooti et al., "Concentrations and dietary exposure to polycyclic aromatic hydrocarbons (PAHs) from grilled and smoked foods," Food Control, vol. 22, no. 12, pp. 2028-2035, 2011.

[8] D. H. Phillips, "Polycyclic aromatic hydrocarbons in the diet," Mutation Research/Genetic Toxicology and Environmental Mutagenesis, vol. 443, no. 1-2, pp. 139-147, 1999.

[9] Z. Xia, X. Duan, W. Qiu et al., "Health risk assessment on dietary exposure to polycyclic aromatic hydrocarbons (PAHs) in Taiyuan, China," Science of the Total Environment, vol. 408, no. 22, pp. 5331-5337, 2010.

[10] United States Army, Corps of Engineers New England District. Five-Year Review Report for the Atlantic Wood Industries Superfund Site, Portsmouth, Virginia, Environmental Protection Agency (US EPA), Washington, DC, USA, 2015.

[11] S. E. Walker, R. M. Dickhut, and C. Chisholm-Brause, "Polycyclic aromatic hydrocarbons in a highly industrialized urban estuary: inventories and trends," Environmental Toxicology and Chemistry, vol. 23, no. 11, pp. 2655-2664, 2004.

[12] P. Strickland, D. Kang, and P. Sithisarankul, "Polycyclic aromatic hydrocarbon metabolites in urine as biomarkers of exposure and effect," Environmental Health Perspectives, vol. 104, no. 5, p. 927, 1996.

[13] P. Strickland and D. Kang, "Urinary 1-hydroxypyrene and other PAH metabolites as biomarkers of exposure to environmental PAH in air particulate matter," Toxicology Letters, vol. 108, no. 2-3, pp. 191-199, 1999.

[14] G. Fillmann, G. M. Watson, M. Howsam, E. Francioni, M. H. Depledge, and J. W. Readman, "Urinary PAH metabolites as biomarkers of exposure in aquatic environments," Environmental Science \& Technology, vol. 38, no. 9, pp. 2649-2656, 2004. 
[15] J. R. Sobus, R. S. DeWoskin, Y. M. Tan et al., "Uses of NHANES biomarker data for chemical risk assessment: trends, challenges, and opportunities," Environmental Health Perspectives, vol. 123, no. 10, p. 919, 2015.

[16] Y. T. Woo and D. Y. Lai, "OncoLogic: a mechanism-based expert system for predicting the carcinogenic potential of chemicals," in Predictive Toxicology, pp. 385-413, Taylor \& Francis Group, London, UK, 2005.

[17] United States Environmental Protection Agency (US EPA), EPA Method 610: Polynuclear Aromatic Hydrocarbons, U.S. Environmental Protection Agency, Washington, DC, USA, 1982.

[18] United States Environmental Protection Agency (US EPA), Record of Decision Operable Units 1, 2 \& 3, Atlantic Wood Industries, Inc., Superfund Site, Portsmouth, VA, USA, 2007.

[19] United States Environmental Protection Agency (US EPA), Risk Assessment Guidance for Superfund Vol 1. Human Health Evaluation Manual, Part E. Supplemental Guidance for Dermal Risk Assessment, U.S. Environmental Protection Agency, Washington, DC, USA, 2004.

[20] United States Environmental Protection Agency (US EPA), Supplemental Guidance for Assessing Susceptibility from EarlyLife Exposure to Carcinogens. Risk Assessment Forum, U.S. Environmental Protection Agency, Washington, DC, USA, 2005.

[21] United States Environmental Protection Agency (US EPA), Exposure Factors Handbook: 2011 Edition, U.S. Environmental Protection Agency, Washington, DC, USA, 2011.

[22] United States Environmental Protection Agency (US EPA), Risk Assessment Guidance for Superfund Vol 1. Human Health Evaluation Manual-Supplemental Guidance, Update of Standard Default Exposure Factors, Final OSWER Directive 9200, U.S. Environmental Protection Agency, Washington, DC, USA, 2014.

[23] United States Environmental Protection Agency (US EPA), Regional Screening Level (RSL) Tables, Mid-Atlantic Human Health Risk Assessment, U.S. Environmental Protection Agency, Washington, DC, USA, 2014.

[24] United States Environmental Protection Agency (US EPA), Regional Screening Level (RSL) Resident Soil Table (TR=1E-06, $H Q=1)$, U.S. Environmental Protection Agency, Washington, DC, USA, 2016.

[25] R. B. Jain, "Trends and concentrations of selected polycyclic aromatic hydrocarbons in general US population: data from NHANES 2003-2008," Cogent Environmental Science, vol. 1, no. 1, article 1031508, 2015.

[26] Z. Li, L. C. Romanoff, S. Bartell et al., "Excretion profiles and half-lives of ten urinary polycyclic aromatic hydrocarbon metabolites after dietary exposure," Chemical Research in Toxicology, vol. 25, no. 7, pp. 1452-1461, 2012.

[27] H. El-Masri, Toxicological Profile for Naphthalene, 1-Methylnaphthalene, and 2-Methylnaphthalene, Agency for Toxic Substances and Disease Registry, Atlanta, GA, USA, 2005.

[28] T. Addis, "The clinical significance of abnormalities in urine volumes," Archives of Internal Medicine, vol. 31, no. 6, pp. 783-796, 1923.

[29] K. Hoffman, L. M. Gearhart-Serna, M. Lorber, T. F. Webster, and H. M. Stapleton, "Estimated tris (1,3-dichloro-2-propyl) phosphate exposure levels for US infants suggest potential health risks," Environmental Science \& Technology Letters, vol. 4, no. 8, pp. 334-338, 2017.

[30] M. Fang, G. J. Getzinger, E. M. Cooper et al., "Effect-directed analysis of Elizabeth river porewater: developmental toxicity in zebrafish (Danio rerio)," Environmental Toxicology and Chemistry, vol. 33, no. 12, pp. 2767-2774, 2014.

[31] A. R. Timme-Laragy, C. J. Cockman, C. W. Matson, and R. T. Di Giulio, "Synergistic induction of AHR regulated genes in developmental toxicity from co-exposure to two model PAHs in zebrafish," Aquatic toxicology, vol. 85, no. 4, pp. 241-250, 2007.

[32] D. M. Wassenberg and R. T. Di Giulio, "Synergistic embryotoxicity of polycyclic aromatic hydrocarbon aryl hydrocarbon receptor agonists with cytochrome P4501A inhibitors in Fundulus heteroclitus," Environmental health perspectives, vol. 112, no. 17, pp. 1658-1664, 2004. 


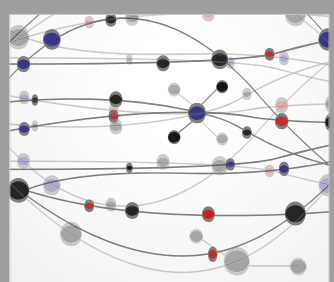

The Scientific World Journal
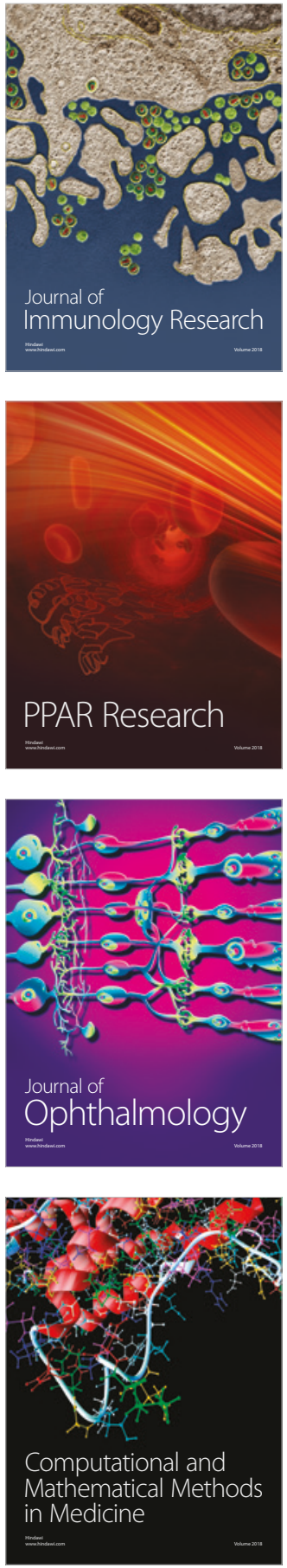

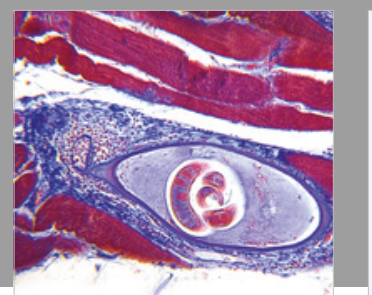

Gastroenterology Research and Practice

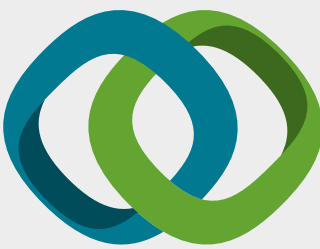

\section{Hindawi}

Submit your manuscripts at

www.hindawi.com
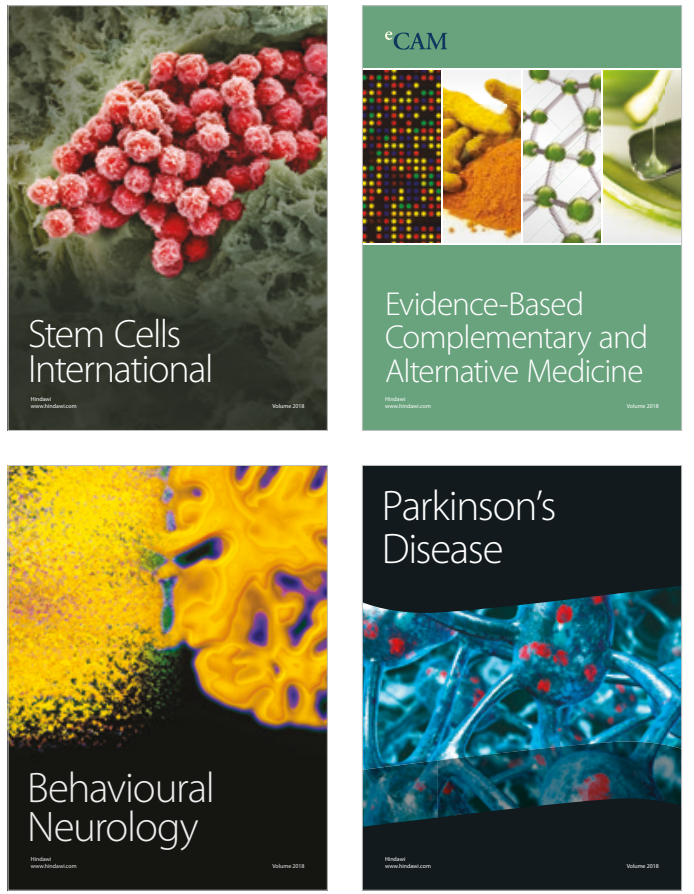

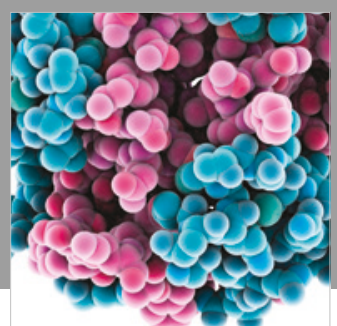

ournal of

Diabetes Research

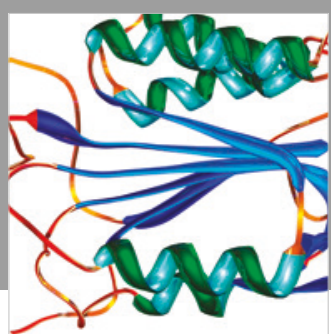

Disease Markers
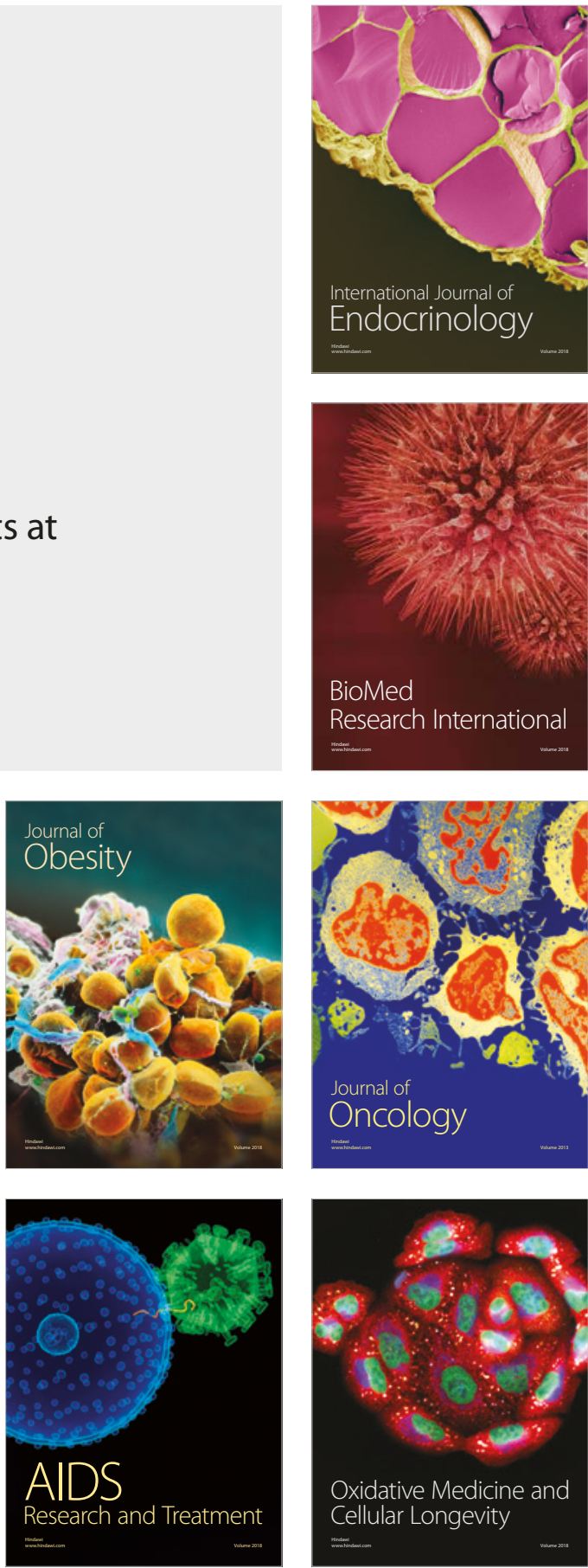